\title{
THE INFLUENCE OF VARIOUS DRYING METHODS ON THE QUALITY OF EDIBLE FLOWER PETALS
}

\author{
Jekaterina Dorozko $^{1 *}$, Daiga Kunkulberga ${ }^{1}$, Irina Sivicka ${ }^{2}$, Zanda Kruma ${ }^{1}$ \\ ${ }^{1}$ Department of Food Technology, Faculty of Food Technology, Latvia University of Life Sciences and Technologies, \\ Rigas iela 22, Jelgava, Latvia, e-mail: Katerina.dorozko@gmail.com \\ ${ }^{2}$ Institute of Soil and Plant Sciences, Faculty of Agriculture, Latvia University of Life Sciences and Technologies,
} Liela iela 2, Jelgava, Latvia

\begin{abstract}
Edible flowers are used in many different styles of cuisine and can be found on menus all over the world. They are receiving renewed interest as rich sources of bioactive compounds. In culinary, edible flowers can be used fresh, dried, candied etc. The drying prolongs shelf life as well as enables the transporting, packaging and use of edible flowers. The aim of this research was to analyse the influence of various drying methods on the quality of edible flower petals. The study was carried out at the scientific laboratories of the Faculty of Food Technology at Latvia University of Life Sciences and Technologies. Such drying methods as drying hot air-drying, microwave drying, and freeze-drying were used in this research. Edible petals of garden marigold (Calendula officinalis L.), common daisy (Bellis perennis L.), and true lavender (Lavandula angustifolia L.) from collection of the Laboratory of Horticulture and Apology, attached to the Faculty of Agriculture of Latvia University of Life Sciences and Technologies, were used as plant material. Total phenolic, total flavonoid content and antioxidant activity were determined in this research. All three drying methods had adverse effects on biologically active compounds of the analysed edible flowers petals. Despite the fact that freeze-drying is the most popular method, microwave drying had the most positive effect in terms of bioactive component content in this study. Analysed samples contained a high amount of phenolic compounds (fresh lavender $1026 \pm 52 \mathrm{mg} \mathrm{GAE} 100 \mathrm{~g}^{-1} \mathrm{DW}$ and fresh marigold $1058 \pm 66 \mathrm{mg} \mathrm{GAE} 100 \mathrm{~g}^{-1} \mathrm{DW}$ ) and showed eligible antioxidant effects.
\end{abstract}

Keywords: total phenolic, drying, edible flowers

\section{Introduction}

The use of edible flowers has been known in Europe since the prehistoric period (Nikitidis, Papiomytoglou, 2011). Nowadays, edible flowers are used in many different styles of cuisine and can be found on menus all over the world. They are receiving renewed interest as rich sources of bioactive compounds as phenols, essential oils etc. (Naczk, Shahidi, 2004). The content of these compounds differs and depends on plant species, cultivar, genotype, growing conditions, harvesting time, food and processing technologies (Naczk, Shahidi, 2006). In culinary, edible flowers can be used fresh, dried, candied etc. Specially prepared and processed, they can make food products healthier as well as visually attractive (Fernades et al., 2017).

The drying prolongs shelf life as well as enables the transporting, packaging and use of edible flowers. It is a lack of studies in the Europe on the current topic therefore the experiments with different plants`species are very important. In Latvia, it is not so much information about the changes of bioactive compounds in drying process for edible petals. That is why this research can be defined as innovative (Aboltins, Kic, 2016). Drying conditions and selection of methodology is essential, for example, the low temperatures in drying process influence the content of biologically active compounds positively, their degradation is much less (Angela, Meireles, 2009).

Garden marigold (Calendula officinalis L.), common daisy (Bellis perennis L.) and true lavender (Lavandula angustifolia L.) are one of the most popular edible flowers in Latvia, used in culinary, food and beverage production, decoration, medicine, perfumery, cosmetics, aromatherapy, for bathing, in decorative horticulture and flowering fields, for attracting bees.
These species can be planted in flowerbeds and herbaceous borders as well as in commercial plantations, also they are easily propagated. Long flowering period and storage possibilities influence growing, marketing and realization of these species or prepared products positive.

Numerous varieties of garden marigold are cultivated in pots and gardens (Nikitidis, Papiomytoglou, 2011). The flowers of the plant are used for therapeutic purposes; they contain saponins, carotenoids, essential oil, sterols, flavonoids and mucilage (Arora et al., 2013). Garden marigold has anti-inflammatory, astringent, healing and emmenagogue properties. It is considered one the best herbs for the treatment of local skin aliments, external bleeding, contusions and burns. It is also considered to have a notable anti-fungal property (Basch et al., 2007). Already in the 12th century it was observed, that "even looking at the golden flowers of the garden marigold improves the sight, cleanses the brain and mends the spirit" (Nikitidis, Papiomytoglou, 2011). There is no doubt that the flowers constitute a dyestuff, it was once used as a spice and to adulterate saffron from the crocus, or to give a yellow colour directly to rice and salads; for this reason, it was called "the poor man's crocus". The French eat veal with marigold, it is sold in the shops in dried form and as wet extract.

Common daisy has been used as a diuretic, antispasmodic, anti-inflammatory, astringent, expectorant, antipyretic, vulnerary, ophthalmic and homeostatic in traditional medicine (Karakas et al., 2011). New leaves can be eaten raw in salads or cooked, noting that the leaves become increasingly astringent with age. Flower buds and petals can be eaten raw in sandwiches, soups and salads. It is also used as a tea and as a vitamin supplement. Flowers have been used 
internally as tea (or the leaves as a salad) for treatment of disorders of the gastrointestinal and respiratory tract (Al-Snafi, 2018).

Lavender is one of the best-known aromatic herbs. Its healing and soothing properties made it a favourite even in antiquity. The uses of lavender in medicine, cosmetic production and in the home are infinite (Nikitidis, Papiomytoglou, 2011). Lavender essential oil has good antioxidant and antimicrobial activities and a significant positive effect on the digestive and nervous systems. Lavender extract prevents dementia and may inhibit the growth of cancer cells, while lavender hydrolyte is recommended for the treatment of skin problems and burns (Prusinowska, Smigielski, 2014). Lavender is used to aromatize confectionery and drinks, while in the form of tea it is calming, relaxing and soothes pain (Nikitidis, Papiomytoglou, 2011).

Drying is a very common preservation method used in deferent foodstuffs. The quality of the final products depends on the technique and the process variables used (Youssef, Mokhtar, 2014). Hot-air-drying is one of most frequently used operations for food dehydration.

Freeze-drying would be the best method of water removal, but it is also expensive method. This method is based on the dehydration by sublimation of frozen sample and the major advantages are protection of bioactive compounds and original shape, colour and flavour of flowers (Zheng et al., 2015).

Microwave drying is alternative to the conventional drying method that allows the product to preserve its useful qualities and is suitable for almost at home. Very important that the heat not only on the surface but also inside the food products or plants. Very high speed of drying gives the quality of the final food product. Xia Fei Shi et al. (2017) reported that microwave drying helps to remain higher content of flavone, vitamin $\mathrm{C}$ and soluble sugars in medicinal chrysanthemum flowers.

The aim of this research was to analyse the influence of various drying methods on the properties and quality of flowers` petals of garden marigold, common daisy and true lavender.

\section{Materials and Methods \\ Plant material}

Fresh marigold, common daisy and true lavender were harvested from collection of the Laboratory of Horticulture and Apology, attached to the Faculty of Agriculture of Latvia University of Life Sciences and Technologies prior to flowering period during September 2018. Green leaves were manually separated from plant. The samples were processed using the following drying methods.

\section{Growing conditions}

The soil at the trial site was strongly altered by cultivation loam. Soil reaction was slightly acidic $\left(\mathrm{pH}_{\mathrm{KCl}} 6.3\right.$ ), with organic matter content of $2.7 \mathrm{~g} \mathrm{~kg}^{-1}$, $\mathrm{P}$ content was $102 \mathrm{~g} \mathrm{~kg}^{-1}$ and $\mathrm{K}$ content was $207 \mathrm{~g} \mathrm{~kg}^{-1}$. Plant care was provided for this collection.

\section{Meteorological conditions}

According to data of the Latvian Environment, Geology and Meteorology Centre, in vegetation period (from May to the end of September), the average temperature was $16.9^{\circ} \mathrm{C}$ (more than long-term observation) and the total quantity of rainfall was about $237.4 \mathrm{~mm}$ (less than long-term observation) in 2018.

In scientific literature it was proved that during the vegetation period the influence of air temperature from 20 to $30{ }^{\circ} \mathrm{C}$ and of the quantity of rainfall of about $600 \mathrm{~mm}$ on the yield of herbs is positive (Rzekanowski et al., 2008). The conclusion is, that in 2018 the meteorological conditions were not optimal for plant biomass creation because of small quantity of rainfall.

\section{Drying Methods}

Hot-air drying: fifty grams of flower petals were distributed uniformly onto trays and dried in a convective dryer (Memmert GmbH, Germany) at $40{ }^{\circ} \mathrm{C}$ (Telfser, Galindo, 2019). The drying time was 6 hours. The moisture content of dried petals was $7.5 \pm 1.0 \%$.

Freeze-drying: before drying fifty grams of flower petals were placed in polyethylene package and frozen at $-18{ }^{\circ} \mathrm{C}$ for 24 hours. The samples were removed from the packaging and placed in Christ Freeze Dryer Alpha 1-2 LD plus at $-60{ }^{\circ} \mathrm{C}$ for 30 hours at 0.046 mbar. The moisture content of dried petals was $9.0 \pm 1.0 \%$.

Microwave drying: a domestic microwave oven (Whirlpool, Type VT254/WH) was used for drying. Petals were spread on the plate inside the microwave and processed until they were completely dry (6-7 min). The microwave output power was $800 \mathrm{~W}$. Final moisture content of dried flowers was $9.5 \pm 1.0 \%$.

\section{Extraction procedure}

Fresh and dried plants were homogenised and for extraction solvent to solid ratio was $1: 10$. Extraction procedure was applied using ethanol / acetone / water (7/7/6 v/v/v) solution in an ultrasonic bath YJ5120-1 (Oubo Dental, USA) at $22 \pm 1{ }^{\circ} \mathrm{C}$ temperature for twelve minutes followed by centrifugation using centrifuge CM-6MT (Elmi Ltd., Latvia) at $3500 \mathrm{~min}^{-1}$ for $5 \mathrm{~min}$ and decantation. Extraction of residues was repeated. The extraction process was done in triplicate.

\section{Analytical methods}

Determination of total phenolic content (TPC) of flower petals extract was determined according to the FolinCiocalteu spectrophotometric method (Singleton et al., 1999). Total phenolic content was expressed as gallic acid equivalents (GAE) $100 \mathrm{~g}^{-1}$ dry weight (DW) of plant material. The absorbance was measured at $765 \mathrm{~nm}$. The total flavonoid content (TFC) was measured by colorimetric method (Tomsone et al., 2012). The absorbance was measured at $415 \mathrm{~nm}$. Total flavonoid content was expressed as the catechin equivalents (CE) $100 \mathrm{~g}^{-1} \mathrm{DW}$ of plant material.

Determination of antioxidant activity (AA) of the petals was measured on the basis of scavenging activities of the stable 2.2-diphenyl-1-picrylhydraziyl (DPPH) radical as outlined by $\mathrm{Yu}$ et al. (2003). The radical 
scavenging activity of extract was measured by 2.2'-azino-bis(3-ethylbenz-thiazoline-6-sulfonic) acid (ABTS) cation assay (Re et al., 1999).

\section{Statistical analysis}

Experimental results are means of three parallel measurements. Data were analysed by Microsoft Excel 2010 and R programme. Analysis of variance ANOVA were used to determine differences among samples. The values were considered to be significantly different when $\mathrm{p}<0.05$. Correlation analysis were performed to analyse association between two continuous variables.

\section{Results and Discussion}

Based on the results obtained and using analysis of variance of factors ANOVA hypothesis that various methods of processing the flower and the flower itself affect various indicators of phenols and flavonoids as well as the antioxidant properties of the petals were put forward.

Table 1

Total phenolic and flavonoid content in petals depending on drying method

\begin{tabular}{|c|c|c|c|}
\hline \multirow[b]{2}{*}{$\begin{array}{l}\text { Flowers } \\
\text { petals }\end{array}$} & \multirow{2}{*}{$\begin{array}{c}\text { Type of } \\
\text { sample } \\
\text { preparation }\end{array}$} & TPC & TFC \\
\hline & & $\begin{array}{c}\text { mg GAE } \\
100 \mathrm{~g}^{-1} \mathrm{DW}\end{array}$ & $\begin{array}{c}\mathrm{mg} \\
100 \mathrm{~g}^{-1} \mathrm{DW}\end{array}$ \\
\hline \multirow[t]{4}{*}{ Lavender } & \multirow{4}{*}{$\begin{array}{l}\text { hot-air dried } \\
\text { freeze dried } \\
\text { microwave } \\
\text { dried } \\
\text { fresh }\end{array}$} & $1135 \pm 26$ & $1868 \pm 14$ \\
\hline & & $1046 \pm 58$ & $1852 \pm 68$ \\
\hline & & $1183 \pm 30$ & $2369 \pm 43$ \\
\hline & & $1026 \pm 52$ & $2586 \pm 48$ \\
\hline \multirow[t]{4}{*}{ Marigold } & \multirow{4}{*}{$\begin{array}{l}\text { hot-air dried } \\
\text { freeze dried } \\
\text { microwave } \\
\text { dried } \\
\text { fresh }\end{array}$} & $954 \pm 82$ & $1903 \pm 59$ \\
\hline & & $1062 \pm 22$ & $1947 \pm 17$ \\
\hline & & $1122 \pm 39$ & $1965 \pm 14$ \\
\hline & & $1058 \pm 66$ & $2522 \pm 19$ \\
\hline \multirow{4}{*}{$\begin{array}{l}\text { Common } \\
\text { daisy }\end{array}$} & \multirow{4}{*}{$\begin{array}{l}\text { hot-air dried } \\
\text { freeze dried } \\
\text { microwave } \\
\text { dried } \\
\text { fresh }\end{array}$} & $801 \pm 90$ & $1190 \pm 2$ \\
\hline & & $1597 \pm 27$ & $2562 \pm 13$ \\
\hline & & $837 \pm 53$ & $1586 \pm 6$ \\
\hline & & $844 \pm 73$ & $1645 \pm 91$ \\
\hline
\end{tabular}

Phenolic compounds are a spacious group of phytochemicals classified as secondary metabolites. In our study total phenolic content for fresh and dried flower petals ranged from 837.7 to $1597.2 \mathrm{mg}$ GAE per $100 \mathrm{~g}$ dry weight sample (Table 1). The amount of flavonoids depended on the type of the flower but also on the method of sample preparation. The loss of phenolic during different drying might be due to the process conditions - temperature and the duration applied (Youssef, Mokhtar, 2014). Previously, a study conducted by Tomsone (2014) on horseradish leaves (Armoracia rusticana L.) showed TPC $2368.48 \mathrm{mg} \mathrm{GAE} 100 \mathrm{~g}^{-1}$ of fresh to

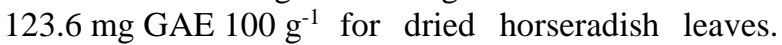
While earlier research studies showed diverse results. Youssel and Mokhtar (2014) studied the effect of drying methods (oven, microwave and freeze drying) on phenolic content of purslane (Portulaca oletacea L.). They reported that the degradation of total phenolics and flavonoids significantly varied according to the drying methods. They noted that extracts of dried leaves always showed lower concentration of total phenolics and flavonoids then from fresh. Chaovanalikit et al. (2012) reported that the shade dried samples had significantly higher phenolics content than freeze- and oven-dried samples. Khattak (2014) found that the total phenolic content of Tagetes erecta ranged from 478.0 to $634.0 \mathrm{mg} 100 \mathrm{~g}^{-1}$ of phenolic compounds in dry weight of the extracts of the flowers. A great influence of the drying method on the extraction of phenols during infusion. In the case of our sturdy on flower's petals, it would be a competitive process for preserving phenolics since similar or better results were obtained with freeze drying method.

Flavonoids are low molecular weight compounds that have a wide diapason of biological activities comprise antibacterial, antioxidant, antiallergic (Fernandes et al., 2017). The flavonoid contents of the samples were determined and presented in Table 1 . The level of flavonoids ranged between 1586.6 to $2586.2 \mathrm{mg}$ $100 \mathrm{~g}^{-1}$ dry weight. The present study showed that the flavonoid content in hot-air $\left(1903.8 \pm 59 \mathrm{mg} 100 \mathrm{~g}^{-1}\right)$, freeze dried (1947.1 $\left.\pm 7.2 \mathrm{mg} 100 \mathrm{~g}^{-1}\right)$ and microwave dried (1965.9 $\left.\pm 14 \mathrm{mg} 100 \mathrm{~g}^{-1}\right)$ marigold are statistically not different $(p>0.05)$. The fresh flower petals of common daisy and marigold showed higher flavonoids content than dried.

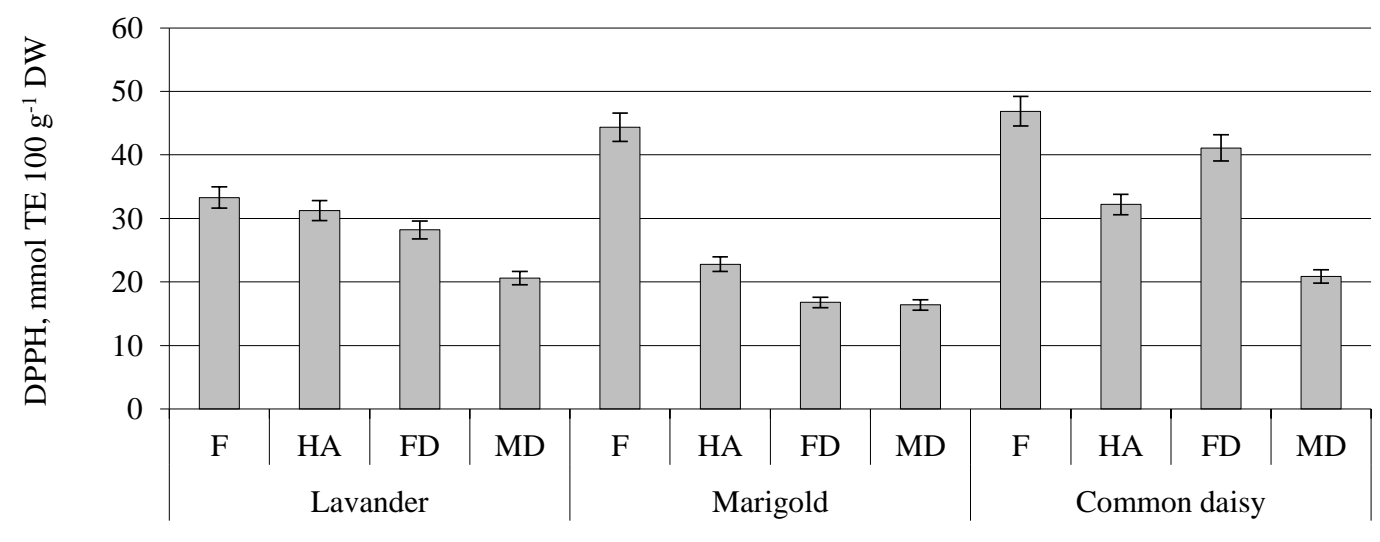

Figure 1. DPPH' scavenging activity in petals depending on drying technique

$\mathrm{F}$ - fresh, HA - hot-air dried, FD - freeze dried, MD - microwave dried 


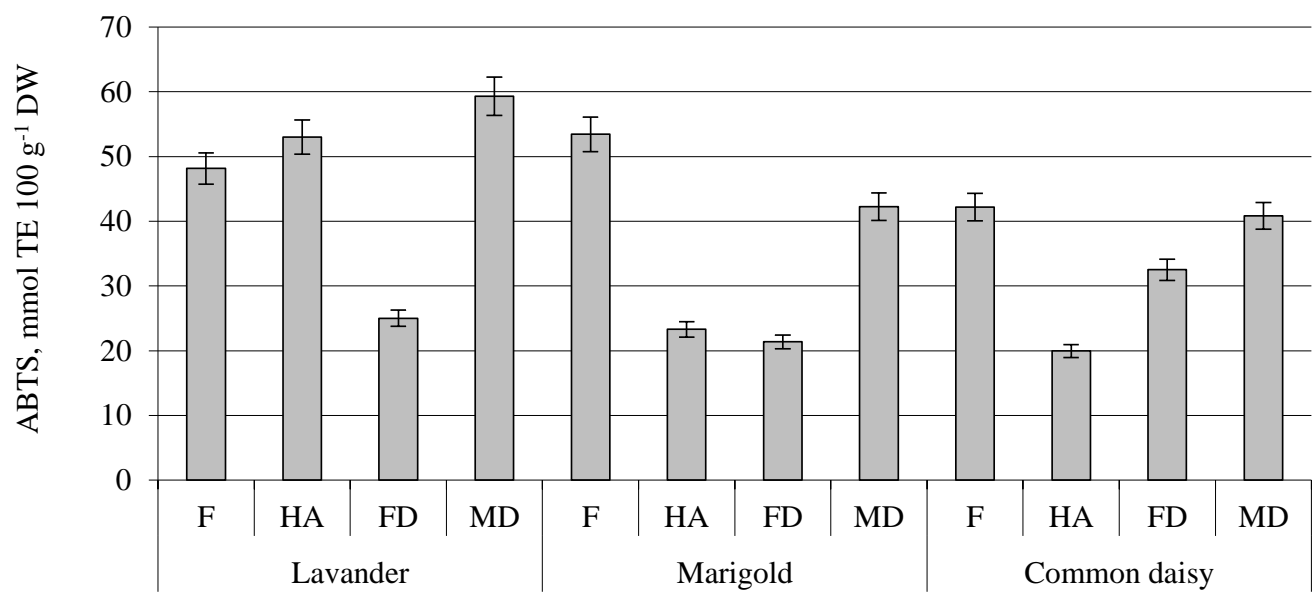

Figure 2. ABTS antioxidant capacity in petals depending on drying technique

$\mathrm{F}$ - fresh, HA - hot-air dried, FD - freeze dried, MD - microwave dried

Scavenging activity of DPPH radicals for all fresh samples of petals showed higher results than dried samples (Figure 1). The highest DPPH scavenging activity was determined in fresh marigold and common daisy petals 44.35 and $46.88 \mathrm{mM}$ TE $100 \mathrm{~g}^{-1} \mathrm{DW}$, respectively. The effect of hot-air, freeze-drying and microwave drying treatments on the ABTS antioxidant capacity of flower petals is shown in Figure 2. The results indicated significant losses in the antioxidant capacity of freeze-dried samples. Increase of antioxidant capacity after drying in lavender could be explained by the release of bound antioxidant compounds during treatment. In fresh plants part of antioxidants are presented in glycosidic linkage with covalent bond and drying accelerates breakdown of cellular constituents and release of them (Wei et al., 2013). Antioxidant capacity of petals may be related to the amount of pigments, total phenols and flavonoids. Since these compounds work as scavengers of the free radicals produced during oxidation reactions.

The non - dispersive are the same then the hypothesis: $\mathrm{H} 0$ that all the defects are the same can reject and accept H1: the antioxidant activity and the amount of phenols amount of flavonoids depend on the type of the flower but also on the method of drying. Explained sum of squares (ESS) 2434692, residual sum of squares (RSS) was 190943 by phenolic and flavonoid content in petals. $\mathrm{P}$ value was $0.0002773 * * *$ which is $<0.05$. $\mathrm{P}$ value by analysis of antioxidant capacity depending on sample preparation was $0.001548^{* *}$ which is also is $<0.05$ than we can discard the null hypothesis and accept the hypothesis about influence of the factor of the flower type and processing of samples preparation.

Table 3

Pearson's coefficients between total phenolic, total flavonoid content and antioxidant capacity for lavender petals

\begin{tabular}{lllll}
\hline & ABTS & DPPH & TFC & TPC \\
\hline ABTS & 1 & -0.247 & 0.356 & 0.241 \\
DPPH & -0.247 & 1 & 0.015 & -0.129 \\
TFC & 0.356 & 0.0152 & 1 & 0.627 \\
TPC & 0.241 & -0.0129 & 0.627 & 1 \\
\hline
\end{tabular}

In order to explore the influence of the phytochemical compounds on petals, Pearson's coefficient was determined (Tables 3-5).

Table 4

Pearson's coefficients between total phenolic, total flavonoid content and antioxidant capacity for marigold petals

\begin{tabular}{lllll}
\hline & ABTS & DPPH & TFC & TPC \\
\hline ABTS & 1 & -0.451 & -0.291 & 0.760 \\
DPPH & -0.451 & 1 & 0.864 & -0.36 \\
TFC & -0.291 & 0.864 & 1 & 0.0691 \\
TPC & 0.760 & -0.361 & 0.0691 & 1 \\
\hline
\end{tabular}

For lavender petals correlation between TPC and TFC was medium ( $\mathrm{r}=0.62)$ but between different antioxidant assays very weak. Strong $(\mathrm{r}=0.86)$ correlation for marigold was between TFC and antioxidant activity DPPH and, also strong $(r=0.76)$ between TPC and ABTS.

Table 5

Pearson's coefficients between total phenolic, total flavonoid content and antioxidant capacity for Common daisy petals

\begin{tabular}{lllll}
\hline & ABTS & DPPH & TFC & TPC \\
\hline ABTS & 1 & -0.140 & -0.113 & 0.209 \\
DPPH & -0.140 & 1 & 0.189 & 0.020 \\
TFC & -0.113 & 0.189 & 1 & 0.75 \\
TPC & 0.209 & 0.020 & 0.753 & 1 \\
\hline
\end{tabular}

If we take the data Pearson's coefficients for common daisy that strong correlation is between TPC and TFC only. The loss of phenolic during different drying might be due to the process condition, the temperature and the duration applied (Youssef, Mokhtar, 2014).

\section{Conclusions}

The findings of this study showed that chosen edible flowers are rich sources of bioactive compounds. All samples contained high amount of phenolics and showed eligible antioxidant effect. The results support the consumption of edible flowers in the diet as functional foods. 
In addition to bioactive compounds, appearance and intended use in cooking and cooking presentation is important and affected by different drying methods. Despite the fact that freeze-drying is the most popular method, microwave drying had the most positive effect in terms of bioactive component content and appearance for flower petals in this study.

\section{Acknowledgment}

The study was financially supported by the project "Scientific Capacity Building in Latvia University of Life Sciences and Technologies -2018” Z28.

\section{References}

1. Aboltins A., Kic P. (2016) Research in some medical plant drying process. In: 15th International Scientific Conference Engineering for Rural Development, Latvia University of Agriculture, Jelgava, p. 1145-1150.

2. Acikgoz F.E. (2017). Edible flowers. Journal of Experimental Agriculture International, Vol. 17(1), p. $1-5$.

3. Al-Snafi A. E. (2018) Traditional uses of Iraqi medicinal plants. Journal of Pharmacy, Vol. 8(8), p. 32-95.

4. Aquino-Bolanos E.N., Urrutia-Hcnandez T.A., CastilloLozano M.L., Chavez-Servia J.L., Verdalet-Guzman I. (2013). Physicochemical parameters and antioxidant compounds in edible squach (Cucurbita pepo) flower stored under controlled atmospheres. Journal of Food Quality, Vol. 36, p. 302-308.

5. Arora D., Rani A., Sharma A. (2013) A review on phytochemistry and ethnopharmacological aspects of genus Calendula. Pharmacognosy Reviews, Vol. 7(14), p. 179-187.

6. Basch E., Bent S., Foppa I. M. (2007) Marigold (Calendula officinalis L.), Journal of Herbal Pharmacotherapy, Vol. 6(3), p. 135-159.

7. Chaovanalikit A., Mingmuang A., Kitbunluewit T., Choldumrongkool N., Sondee, J., Chupratum, S. (2012) Anthocyanin and total phenolics content of mangosteen and effect of processing on the quality of mangosteen products. International Food Research Journal, Vol.19(3) p. 1047-1053.

8. Fernandes L., Casal S., Pereira J.A., Saraiva J.A., Ramalhosa E. (2017) Edible flowers: A review of the nutritional, antioxidant, antimicrobial properties and effects on human health. Journal of Food Composition and Analysis, Vol. 60, p.38-50.

9. Grzezczuk M., Wesolowska A., Jadczak D., Jakubowska B. (2011). Nutritional Value of Chive Edible Flowers. Acta Sci. Pol., Hortorum Cultus, Vol. 10(2), p. 85-94.

10. Guiné R., Santos E., Correia P. (2017). Edible flowers: knowledge and consumption habits. Acta Scientific Nutrition Health, Vol. 3, p. 18-22.

11. Karakas F. P., Karakas A., Coskun H., Turker A. U. (2011) Effects of common daisy (Bellis perennis L.) aqueous extracts on anxiety-like behaviour and spatial memory performance in Wistar albino rats. African Journal of Pharmacy and Pharmacology, Vol. 5(11), p. $1378-1388$

12. Khattak K. (2014) Antioxidant activities and phytochemicals of Tagetes Erecta flowers as affected by drying methods. Journal of Applied Environmental and Biological Sciences, Vol. 4(95) p. 253-262.

13. Koikea A., Barreiraa J.C., Barros L., Santos-Buelgac C., Villavicencio A.L. Ferreira I.C. (2015) Edible flowers of
Viola tricolor L. as a new functional food: antioxidant activity, individual phenolics and effects of gamma and electron-beam irradiation. Food Chemistry, Vol. 179, p. 6-14.

14. Kucekova Z., Mlcek J., Humpolicek P., Rop O. (2013) Edible flowers - antioxidant activity and impact on cell viability. Central European Journal of Biology, Vol. 8(10), p. 1023-1031.

15. Loizzo M.R., Pugliese A., Bonesi M., Tenuta M.C., Menichini F., Xiao J., Tundis R. (2015) Edible flowers: A rich source of phytochemicals with antioxidant and hypoglycemic properties. Journal of Agricultural and Food Chemistry, Vol. 64 (12), p. 2467-2474.

16. Naczk M., Shahidi F. (2004) Extraction and analysis of phenolics in food. Journal of Chromatography A, Vol. 1054 (1-2), p. 95-111.

17. Navarro-González I., González-Barrio R., GarcíaValverde V., Bautista-Ortín A.B., Periago M.J. (2015) Nutritional composition and antioxidant capacity in edible flowers: Characterization of phenolic compounds by HPLC-DAD-ESI/MS ${ }^{n}$. International Journal of Molecular Sciences, Vol. 16, p. 805-822.

18. Nikitidis N., Papiomytoglou V. (2011) Green plants \& herbs of Greece. Rethymno: Mediterraneo Editions. $135 \mathrm{p}$.

19. Petrova I., Petkova N., Ivanov I. (2016) Five edible flowers - Valuable source of antioxidant in human nutrition. International Journal of Pharmacognosy and Phytochemical Research, Vol. 8(4), p. 604-610.

20. Prusinowska R., Smigielski K. B. (2014) Composition, biological properties and therapeutic effects of lavender (Lavandula angustifolia L.). A review. Herba Polonica, Vol. 60(2), p. 56-66.

21. Re R., Pellegrini N., Proteggente A., Pannala A., Yang M., Rice-Evans C. (1999) Antioxidant activity applying an improved ABTS radical cation decolorization assay. Free Radical Biologyand Medicine, Vol. 26, p. 1231-1237.

22. Rzekanowski C., Marynowska K., Rolbiecki S., Rolbiecki R. (2008) The influence of selected meteorological factors on some elements of the yield of four herb species cultivated under irrigation conditions. Acta Agrophysica, Vol. 12(1), 163-171 (in Polish).

23. Singleton V.L., Orthofer R., Lamuela-Raventos R.M. (1999) Analysis of total phenols and other oxidation substrates and antioxidants by means of Folin-Ciocalteu reagent. Methods in Enzymology, Vol. 29, p. 152-178.

24. Skrajda M.N. (2017) Phenolic compounds and antioxidant activity of edible flowers. Journal of Education, Health and Sport, Vol. 7(8), p. 946-956.

25. Telfser A., Galindo F.G. (2019) Effect of reversible permeabilization in combination with different drying methods on the structure and sensorial quality of dried basil (Ocimum basilicum L.) leaves. LWT-Food Science and Technology, Vol. 99, p. 148-155.

26. Tomsone L., Kruma Z., Lepse L. (2012) Influence of genotype and harvest time on the phenolic content of horseradish (Armoracia rusticana L.) roots. In: Research for Rural Development 2012: Annual $18^{\text {th }}$ international scientific conference proceedings, Jelgava, 16-18 May 2012 / Latvia University of Agriculture. Jelgava: LLU, Vol. 1, p. 124-130.

27. Tomsone L., Kruma Z. (2014) Influence of freezing and drying on the phenolic content and antioxidant activity of of horseradish and lovage. In: $9^{\text {th }}$ Baltic Conference on Food Science and Technology "Food for Consumer Well- 
Being” FOODBALT 2014 Conference Proceedings, Jelgava, Latvia University of Agriculture, p. 192-197.

28. Zheng M., Xia Q., Lu S. (2015) Study on drying methods and their influences on effective components of loguat flower tea. LWT-Food Science and Technology, Vol. 63(1), p. 14-20.

29. Youssef K.M., Mokhtar S.M. (2014) Effect of drying methods on the antioxidant capacity, color and phytochemicals of Portulaca oleracea L. leaves. Journal of Nutrition \& Food Sciences, Vol. 4, p. 1-6.

30. Yu L., Haley S., Perret J., Harris M., Wilson J., Haley S. (2003) Antioxidant properties of bran extracts from
Akron wheat grown at different locations. Journal of Agriculture and Food Chemistry, Vol. 51, p. 1566-1570.

31. Wei E., Chan C., Lye P.Y, Eng S.Y., Tan Y.P. (2013) Antioxidant properties of herbs with enhancement effects of drying treatments: A synopsis. Free Radicals and Antioxidants, Vol. 3, p. 2-6.

32. Xiao-Fei S., Jian-Zhou C., Yan-Fen Z., Cun-Oi L., XiaoOin Y. (2017) Nutritional and active ingredients of medicinal chrysanthemum flower heads affected by different drying methods. Industrial Crops and Products, Vol. 104, p. 45-51. 